\title{
SOBRE EL ET APODÍCTICO MEDIEVAL
}

\author{
María Márquez Guerrero
}

Las nuevas corrientes de la Lingüística han señalado la necesidad de superar los límites de la gramática estructural tradicional, que entendía el estudio de la lengua como una descripción inmanente del sistema, y que partía de la oración como unidad básica del análisis. Frente a esto, se propone un enfoque comunicativo, que estudie el funcionamiento de las unidades en el discurso, tomando el texto como unidad lingüística comunicativa fundamental. Texto significa etimológicamente "tejido", totalidad de elementos que se entrelazan; el carácter cerrado y la coherencia son rasgos básicos de su definición.

Buena parte de la investigación en Lingüística Textual se ha dedicado al estudio de los medios de cohesión entre los que hay que destacar los elementos de relación: preposiciones y conjunciones. El estudio de la conjunción copulativa tiene que desarrollarse tanto en el plano oracional como en el plano textual, en la medida en que en ocasiones relaciona "la oración en que se halla con el sentido general de lo que se viene diciendo" (Gili Gaya: 1972, 326).

Como ha señalado Ana $\mathrm{M}^{\mathrm{a}}$ Barrenechea (1979, 7-19), al plantear el estudio de la conjunción copulativa es necesario tener en cuenta dos aspectos: la naturaleza semántica y la naturaleza sintáctica de las relaciones que establece. El primero de ellos es objeto de otro trabajo en curso. En el presente vamos a ocuparnos del análisis del aspecto sintáctico en el castellano antiguo y en el español moderno.

Como nexo coordinante, la conjunción copulativa tiene el valor de relación no jerárquica entre dos o más elementos, frente a la subordinación, que indica integración de un contenido en otro.

Como enlace de elementos de función equivalente, la copulativa presenta prácticamente los mismos usos. Quizás pueda comentarse el empleo, ya señalado por Bello, de la conjunción anteponiéndose también al primero de los miembros enlazados por ella, construcción que hoy no se conserva:

"et si quieres muchas heredades et huertas, et muy fermosas et muy delectosas..." (Conde Lucanor, 76)

Con el sentido de "si quieres muchas heredades y huertas muy hermosas y muy deleitosas". Claro que también podríamos considerar que se trata de una oración compuesta por coordinación con el segundo verbo elíptico con el sentido de "si quieres muchas heredades y huertas y (las quieres) muy hermosas y muy deleitosas". Con este último valor, 
la construcción sigue dándose hoy. Ana $\mathrm{M}^{a}$ Barrenechea menciona ejemplọ como "se interesan, y con fundamento".

Nos han interesado especialmente los casos en los que la copulativa une elementos de funciones no equivalentes; nos referimos concretamente al empleo de la copulativa introduciendo la apódosis de oraciones condicionales, causales, temporales, finales y concesivas:

"E quando ovieron todos visto el cueruo negro entre los cigoñinos, e fueron contra la madre e matáronla" (Libro de los enxemplos, 749)

"E commo quier que ellos eran muy esforçados en la batalla, e mucho lo eran más cada que el conde oyen nonbrar 'Castiella'" (Crónica General, Marden, 133; Menéndez Pidal, 403b, 46 suprime la conjunción)

"Et commo el Diablo sabe todas las cosas passadas et sabia el coydado en que vinia aquel omne, et preguntol por que vinia tan triste" (CL, 235)

"començaron a esforçar a aquellos sus mayorales fasta que les fizieron començar la contienda, et dando a entender cada uno dellos a su mayoral quel guardava, et guardavanse los unos et los otros et fazian tornar todo el daño sobre el león et sobre el toro" (CL, 138).

"Et avn por que mas sepades que por uirtud delas buenas obras aluenga Dios la vida a los omnes, et asy lo dize la ley" (Contra hadas, fol. 199v)

En todos estos ejemplos, la conjunción introduce la apódosis cuando se antepone la prótasis. La presencia de la conjunción introduciendo la oración "principal" ya fue señalada por Karl Pietsch (1925):

"E quando el caçador abrio el odre para lo mostrar al tendero, e cayo del vna gota" (LEngaños, Bonilla, 37, 488)

"E quando lo supo el rey, e fue muy sañudo" (174b)

"E por que Ercoles fue muy sesudo e bienaventurado e muy entendido de las cosas que avian de benir, e nunca en España ovo rrei que su mandado quisiese pasar" (Crón. Gen., $1344,58)$

"Ca si me tu mataras e me abrieras, e fallaras en las mis entrannas piedra preciosa" (Berlan, fol. 125)

También delante del núcleo predicativo oracional cuando el sujeto está constituido por largas enumeraciones o por un núcleo especificado por oraciones de relativo, o cuando entre ambos se introduce algún inciso ${ }^{1}$ :

\footnotetext{
${ }^{1}$ Advierte Pietsch acerca de la costumbre de los antiguos editores de no poner coma delante de la conjunción, ni tomar tampoco la postura de suprimirla, con lo cual el sentido se deja "tan oscuro... que ni con linterna se dará con él" (37, n. 2)
} 
"e ellos que lo desamauan mortalmente e lo tenian en la mayor cuyta que podian, e dieronle muy grandes golpes sobre el escudo" (Demanda 130a)

"e fecha la confision e tomada la penitençia e leuantandose en los pies, e se fue a oyr misa" (Decam. Cast., 197, 5)

Según Galmés (1956), la presencia de et ante la apódosis se da en las lenguas semíticas, especialmente en oraciones condicionales. Aunque reconoce que "el giro" existía también en griego y en latín -y, como consecuencia, en las lenguas románicas-, considera que en el caso del castellano el influjo árabe explicaría, no su existencia, pero sí su productividad y pervivencia a lo largo de los siglos XIV y XV (en el resto de las lenguas romances, en general, desapareció rápidamente).

Dardel (1983) se ocupa de estas construcciones, que, según sus investigaciones, remontan a la época del románico común tardío, pues su existencia está documentada en todas las hablas románicas menos en el sardo. Junto a et, también se utilizó si para la "introducción de un término no inicial". La función de estos elementos sería la de "marquer la place respective de la dépendante et de la régissante"; y añade: "ce système n'est pas dépourvu d'une certaine logique, dans la mesure où ET vient à introduire soit une autonome, soit una régissante, laquelle possède souvent une certaine autonomie à l'égard de la dépendante. [...] ET sert à expliciter la relation sémantique d'interdépendance..." (102103). Así pues, para Dardel et tiene en estos contextos una función de marcador semántico y un valor demarcativo.

Aparte de estos contextos señalados, la conjunción aparece también delante del núcleo del predicado oracional cuando le precede alguno de sus complementos:

"Et agora, con el ayuda dela alteza dela uirtud dela gracia del Spiritu Santo, et veredes commo uos los alcançare por mjntirosos sobresta rrazon" (Contra Hadas, fol. 197v)

"Et vos, señor conde Lucanor, con estos vuestros vezinos passat assí; con el que avedes tales debdos que en toda guisa quered que sienpre seades amigos, et fazedle sienpre buenas obras".

En ocasiones, la conjunción aparece acompañada de un adverbio o expresión de carácter anafórico:

"quando llegare aquel que significó por su llegamiento la muerte, al grado daquel a quien se llegó corporalmente o a los grados de las quadraturas, et estonce será la ora de la muerte" (Libro de los juicios de las estrellas, fol. 53)

"et, commo uos dixe, por que nos somos mal nudridos et mal acostunbrados por las malas conpannas del mundo, et somos muy desolutos et muy desobedientes a Dios, et por ende aprenden los nuestros fijos..." (C.h., fol. 202r)

Estos adverbios o expresiones anafóricas aparecen también, en estos mismos contextos sin la conjunción copulativa: 
"pero, porque todo consejero, si leal es, non deve catar sinon por dar el mejor consejo et non catar su pro, nin su daño..., por ende yo non dexaré de vos dezir..." (C.L., 254)

Aparte de la conjunción, en esta posición aparecen esporádicamente otros elementos:

"et si fuere el grado el que se pone con la estrella siguiente al grado que se pone, pues la estrella aun no es puesta" (en al-Battani, Cánones, 81)

"Pena non meresçe, pues las planetas et las fadas et las otras cosas sobredichas que dizen los sabios, ca por fuerza le fizieron pecar" (C.h., fol. 198v).

En primer lugar, hemos de preguntarnos sobre la función de la conjunción copulativa en una oración compuesta por subordinación -por tanto, uniendo elementos no equifuncionales-, donde, por otra parte, la dependencia sintáctica entre los constituyentes está expresada por un nexo subordinante. En todos los ejemplos que hemos citado, se da la circunstancia de una alteración del "orden sintáctico básico" o "habitual" en nuestra lengua: $\mathrm{S}+\mathrm{V}+\mathrm{O}$; Subordinante - Subordinado. Como es sabido, tradicionalmente se ha hablado del orden "normal" de los elementos en la lengua utilizando un criterio sintáctico y siempre aplicándolo en el nivel de la oración; toda ordenación que no se sujetara a esa secuencia "habitual" se consideraba marcada, y se explicaba por un predominio de la afectividad sobre la lógica.

Sin embargo, como ha indicado Gutiérrez Ordóñez $(1997,29)$, el orden no está determinado exclusivamente por las funciones sintácticas ni las semánticas; tan determinantes como estas son las funciones informativas, que se manifiestan a través de índices como el orden de palabras, la entonación, pausas, posibilidad de elipsis, etc.

En situaciones neutras, el soporte (elemento que transmite la información conocida) ocupa el primer lugar, mientras que el aporte (elemento que contiene la información novedosa) se sitúa en la parte final.

Según este punto de vista, en los ejemplos citados no hay alteración de ningún orden básico, sino un desajuste entre funciones informativas y funciones sintácticas, y una clara prioridad de las primeras sobre las segundas ${ }^{2}$. Ya se trate de anteposición temática (la prótasis constituye el soporte informativo), de focalización (el elemento antepuesto contiene una información nueva que se desea poner de relieve) o de topicalización (el elemento señala el ámbito en el que es válido lo enunciado), ese segmento ha sufrido una especie de desligamiento de la estructura predicativa básica. Ese parcial desgajamiento se manifiesta en el orden -estos elementos ocupan la posición inicial-, además de en la existencia de una pausa más o menos marcada y en el contraste tonal.

\footnotetext{
${ }^{2}$ Narbona ha hablado de esa asimetría entre las funciones informativas y las sintácticas como "uno de los rasgos que caracterizan la peculiar andadura sintáctica coloquial", a la que define como "parceladora" y "quebrada" (1986, 261-262). Las relaciones estrictamente funcionales son las mismas que se identifican en la lengua culta pero "se ofrecen fragmentariamente y según el lugar que, desde un punto de vista fundamentalmente informativo, el hablante les asigna".
} 
Por otra parte, la asimetría entre la función informativa y la sintáctica -una, que impone el orden soporte-aporte, y otra, el de S + V + O, Subordinante-Subordinado- puede llevar a interpretaciones ambiguas. El orden no sirve en estos casos para averiguar las dependencias sintácticas.

Para evitar esta ambigüedad, desde los orígenes es frecuente que, en los casos de anteposición temática, aparezca un elemento redundante con valor anafórico que recoge el elemento tematizado integrándolo en la estructura oracional; por ejemplo, una forma pronominal que indica la función sintáctica del elemento tematizado:

"La calçada de Quynea, ivala traspasar" (Cid)

Según reconoce la Real Academia en su Esbozo (1998; 3.17.1, 500), los factores principales para expresar la unidad de la oración compuesta son la entonación y las palabras de enlace, y añade que "aunque de ordinario ambos factores concurren en la mayoría de los casos, uno de ellos puede faltar o debilitar su expresividad en determinadas ocasiones".

Los tópicos, focos o elementos tematizados se manifiestan, entre otros índices, por medio de la curva de entonación, que se caracteriza por un tonema final de semianticadencia. Cuando la subordinada antepuesta tiene una extensión considerable, puede ocurrir que la función distintiva de la entonación se debilite. En estas situaciones, ni el orden ni la entonación sirven para establecer la unidad oracional. Por este motivo, puede existir gran dificultad en la percepción de la relación lógica, de la dependencia sintáctica que existe entre los elementos. No es extraño que, ante estas circunstancias, se busquen otros medios para marcar esas relaciones; en el caso de et ante apódosis, nos referimos concretamente a las relaciones constitutivas "que hacen referencia a la relación de pertenencia entre las partes y el todo en el que se integran” (Jiménez Juliá: 1987, 307-310). La conjunción indica que la secuencia que introduce no está integrada en la anterior como elemento subordinado. Su función en estos contextos sería la de marca de relación constitutiva, índice de pertenencia o integración de las dos proposiciones en una unidad sintáctica de orden superior. Con un valor continuativo, señala que la estructura sintáctica no está completa; de aquí se derivan su función demarcativa y su valor anafórico.

Su función es análoga a la de un nexo discontinuo correlativo: si... et, quando... et, aunque... et; el valor de la partícula et es anafórico; con esto queremos decir que para su interpretación hemos de remitirnos a un elemento precedente en el discurso. Su contenido, por tanto, cambia en función de esa referencia: puede ser consecutivo -generalmente en las causales y condicionales-, temporal, final o concesivo.

Al tratar de los tópicos, temas y focos, hemos hablado de un tonema final de semianticadencia y de pausa, probablemente, la forma et, precedida de pausa, se articularía con mayor intensidad que en los casos en que funciona como marca de relación conectiva (relación parte-parte, conjunción o enlace conjuntivo), y, tal vez, fuera seguida de una pausa muy breve situada entre ella y la suboración que introduce.

En ocasiones, puede ocurrir que la oración compuesta condicional, causal, temporal, concesiva o final -con el orden envolvente prótasis-apódosis- funcione, toda ella en 
conjunto como una completiva, generalmente como objeto. En estos casos, la apódosis pospuesta no va introducida por et, sino por la forma que actuando como marca de relación conectiva, índice de subordinación, y también con un valor demarcativo (señala que la secuencia que introduce no es una subordinada en segundo grado). La repetición de que se da también en aquellos casos en que los núcleos de las unidades relacionadas están separados por otros elementos (incisos, oraciones de relativo, largas enumeraciones):

"Estonçe le dixo Saladín quel plazía desto que ella le dizía, et dixol que la respuesta de la pregunta que ella fiziera, que era esta..." (C.L., 264)

"parat mientes que maguer que la entençion del raposo era para engañar al cuervo, que sienpre las sus razones fueron con verdat" (C.L., 81)

"Et desi, temiendose que sy las assy dexasse ally, que los traydores que alquel mal les fizieran que se arrepentrien..." (Versión amplificada...)

"prometio a Santa Maria que sy selos diese biuos, que darie vna toca de seda" (Cantigas de Santa Maria en prosa castellana, XVIII)

Dardel señala que la reprise de un subordinante se remonta a una época más tardía que la que corresponde al et apodíctico, concretamente al románico tardío B, pues se da en todas las lenguas románicas menos en sardo y en rumano. Opina que es un fenómeno que "ha desaparecido casi totalmente de las hablas románicas modernas" $(1983,151)$, hecho con el que no estamos de acuerdo ${ }^{3}$. Aunque reconoce que la forma que tiene la función de explicitar la subordinación y compensar "un bruit" que produce una subordinada en segundo grado o un complemento o un sujeto demasiado largos, afirma que "il s'agit, au moins à l'origine, de la simple répétition du subordonnant, quel qu'il soit" (152), haciendo referencia a las repeticiones de QUOMODO y de SI.

No creemos que se trate de la simple repetición de un nexo subordinante, sino de un elemento con función de marcador sintáctico. El "ruido" del que habla Dardel hace referencia a la dificultad de percibir la relación de subordinación debido a la prioridad de las funciones informativas sobre el orden sintáctico lineal. Estamos ante estructuras características de un código oral (textos antiguos, todavía sujetos a la organización o impronta de lo oral; textos orales modernos), debido al hecho de que es en el habla donde se da un mayor predominio de las funciones informativas sobre las sintácticas, mayor flexibilidad o una menor sujeción a los esquemas sintácticos.

En nuestra opinión, se trata de estructuras emparentadas, independientemente de que una de ellas sea anterior en el tiempo. Por otra parte, creemos que estas estructuras no han

\footnotetext{
${ }^{3}$ Oraciones como "me dijo que si no quería ir al cine, que me fuera a dar una vuelta al parque", son estructuras muy frecuentes, de uso general en la lengua hablada. Luego la desaparición que señala Dardel sólo puede aplicarse a la lengua escrita, donde tampoco fue tan temprana como él señala; así es muy frecuente en el Quijote. Resulta destacable que Dardel que utiliza la variable oral / escrito como fundamento de su tesis sobre el sistema de las conjunciones en románico común, luego no la aplique a la hora de explicar estas estructuras concretas.
} 
desaparecido de las lenguas románicas. La estructura que...que se conserva, sin ninguna duda, en el español hablado; por lo que se refiere a la estructura de la copulativa apodíctica, se conserva, transformada, en la lengua hablada donde se ha sustituido la conjunción por otros elementos, especialmente pues, que realizan una función similar en estos contextos. Veamos los datos en los que nos apoyamos para postular una continuación de estas construcciones.

El afán de cohesión es un rasgo que comparten el castellano de los orígenes y la lengua hablada de hoy. En ambas situaciones, se da la presencia de factores que pueden ocasionar dificultades para la correcta percepción de las dependencias sintácticas, y, por tanto, ambigüedades en la interpretación del sentido. El habla tiene un carácter esencialmente temático. Teniendo en cuenta estos condicionamientos comunes, sería lógico esperar una continuación de las estructuras que estudiamos.

En la traducción de obras del árabe, el fa de apódosis corresponde a las formas et, que y pues. Ya hemos citado el ejemplo con pues de los Cánones de al-Battani; Galmés cita un ejemplo del Calila traducido así por Alemany:

"Et que no encuentro nada cierto, pues razon es que siga la religión de mis padres".

Igualmente hemos observado el uso de expresiones como et estonce, et por ende; con el tiempo, los adverbios pudieron asumir los valores de la copulativa en estos contextos.

Estos casos nos ponen sobre la pista de lo que podría ser una continuación de estos esquemas oracionales.

En los mismos contextos que la construcción con et, determinadas por los mismos factores, encontramos en las encuestas del habla urbana de Sevilla estructuras donde elementos como pues o entonces introducen la apódosis de oraciones condicionales, causales, temporales o concesivas cuando la prótasis se antepone.

Estos elementos aparecen también cuando se interrumpe el avance informativo por la intercalación de elementos (especificaciones relativas o incisos); las estructuras de las que hablamos se dan por igual en el nivel popular y en el medio:

"soy dormilón, y como me levanto todos los días a las siete de la mañana, pues el martes me gusta a mí levantarme tarde" (P1V2)

“... me levanto, bueno no sé, según lo que tenga que hacer. Si no tengo nada que hacer, pues hasta que me abata el sueño y me levanto" (P1V1)

"pero vamos, no daba en casa porque no hacía falta; cuando hacía falta, pues lo tenía que dar" (P2V2)

“cuando empezó el curso, pues fui a hablar con el profesor y me dijo..." (P2H1)

"y ahora, cuando termine con esto, pues voy para allá para su casa" (M1 $1 \mathrm{H} 1)$ 
Con tópicos:

"Vamos, que yo me alejo una mijita; y las discotecas, pues de vez en cuando voy" (P1V4)

"Bueno, amigos amigos tengo cuatro o cinco. Gente conocida, pues conozco a bastante, ¿no?” (M1H1)

Con complementos antepuestos temáticamente:

"Bueno, es que suelo repartir los fines de semana... Un fin de semana aquí, en Sevilla, pues lo puedes pasar yendo a alguna fiesta" (M1V2)

Hemos encontrado dos casos en los que la apódosis está introducida por la copulativa; creemos, sin embargo, que no se trata de una continuación del et apodíctico medieval, sino de estructuras sintácticas quebradas:

"Aquello es precioso. Vamos, a mí me encantaba aquello, pues si no tenía ganas de dar clase, y te perdías por allí, por los campos" (M1H1)

"Y como yo me fui de veraneo en julio y ella se iba en agosto, y ya no nos vimos hasta octubre" (M1H1)

Algunos autores se han ocupado de estos esquemas oracionales propios de la lengua hablada. Ynduráin y Beinhauer consideran que las formas como pues o entonces en estos contextos son palabras "despojadas de sentido y utilizadas como mero soporte en la conversación", ; su función se reduciría a rellenar vacíos o lagunas que amenazan la fluidez de la enunciación ${ }^{5}$.

Narbona considera que lo que verdaderamente diferencia la lengua coloquial de la lengua culta es la preferencia "por esquemas en los que la trabazón entre los miembros sea mínima" (1986, 261-262). En cuanto a la construcción que estudiamos, la ve como manifestación de la "liberación de una cobertura sintáctica dominadora... que se efectúa a través de muy variados recursos desmembradores, entre ellos el más elemental consiste en intercalar algunos de los términos o expresiones de débil carácter ilativo” (269-70).

Desde nuestro punto de vista, en estas estructuras el carácter fragmentario es una consecuencia de la prioridad que el hablante da a las funciones informativas; pero precisamente esa partícula pues no es un "recurso desmembrador", sino, al contrario, un elemento integrador que busca compensar la asimetría que se crea entre las funciones informativas y las sintácticas para asegurar la cohesión del discurso.

\footnotetext{
4 “Más sobre lenguaje coloquial”, Español Actual, nำ, 1966, p.3.

5 "Dos tendencias antagónicas en el lenguaje coloquial español", Español actual, 6, 1955, pp. 1-2; no obstante concede que pues "constituye un modo de 'puentecillo' cuyo paso le da tiempo para formar cómodamente la frase principal y decisiva de su enunciación"; y reconoce que funciona como elemento que realza lo esencial de cuanto el hablante quiere enunciar.
} 
En esta misma dirección se encuentran las ideas de Cortés Rodríguez, quien también relaciona la existencia de estos esquemas oracionales con el esfuerzo por conseguir un texto cohesionado; distingue entre un pues cuya función es simplemente suprimir el horror vacui, de otro pues que se da en los casos que hemos estudiado (1991, 38-42).

Fuentes Rodríguez estudia estos términos en cuanto elementos de relación consecutivos-continuativos (1983, 92-95; 1987, 145).

Para Moya Corral la partícula pues tiene "un evidente carácter consecutivo" y una función demarcativa, pues "sirve para establecer la separación entre la proposición introducida por como, si, cuando y la que ella misma inicia" (1981, 87-88). Explica su uso por razones de expresividad (89).

El hecho de que su aparición se dé en los mismos contextos en los que en castellano antiguo aparecía et, es decir, en textos en los que se ha producido un desajuste entre funciones informativas y sintácticas, nos lleva a considerar que estos elementos tienen una función integradora, y su presencia, en último término, viene determinada por el afán de conseguir un texto coherente y preciso.

Estos esquemas oracionales que estudiamos responden exactamente a las que los gramáticos de lengua inglesa llaman oraciones escindidas. Con esta expresión se refieren a "una construcción sintáctica muy frecuente entre las lenguas, en la cual se focaliza un elemento de una oración "sacándolo" de esta y uniéndole de nuevo a ella mediante la cópula” (Moreno Cabrera: 1985-86, 187).

La construcción del castellano antiguo con et podría ser interpretada como una variante de ciertas estructuras sintácticas en las que se da un "cruce entre dos procedimientos de relacionar entre sí las oraciones: uno discursivo, que consiste en la utilización de un elemento con valor fórico, et, y otro de sintaxis intraoracional: la subordinación mediante una conjunción" (168).

De aceptarse esta hipótesis, constituiría un argumento más que mostraría que no existe una ruptura entre la sintaxis del discurso y la de la oración.

\section{BIBLIOGRAFÍA}

Alarcos Llorach, E.: Gramática de la lengua española, Madrid, Espasa-Calpe, 1995

Alcina Franch, J. y Blecua J.M.: Gramática española, Barcelona, Ariel, 1983

Alonso, D.: "Sintagmas no progresivos", Alonso, D. y Bousoño, C.: Seis calas en la expresión literaria española, Madrid, Gredos, 1979, pp.23-41.

Álvarez Pereira, J. Mํㅗㄹ "La coordinación de oraciones en el siglo XIV. Análisis de algunos documentos notariales hallados en la catedral de Coria", Actas del I CIHLE, Madrid, I, 1988, pp. 257-270.

Badía Margarit, A.: "La frase de la Primera Crónica General en relación con sus fuentes latinas”, RFE, XLII, 1958-59, pp. 179-210. 
---- "Dos tipos de lengua, cara a cara", Studia Philologica. Homenaje ofrecido a Dámaso Alonso, I, Madrid, 1960, pp. 115-139.

Barrenechea, A. Ma: "Problemas semánticos de la coordinación”, Estudios lingüísticos y dialectológicos. Temas hispánicos, Buenos aires, 1979, pp. 7-20.

Beinhauer, "Dos tendencias antagónicas en el lenguaje coloquial español", Español actual, 6, 1955, pp.

Bello, A.: Gramática de la lengua castellana, Madrid, EDAF, 1988.

Bobes Naves, $\mathrm{M}^{\mathrm{a}}$ del C.: "La coordinación en la frase nominal castellana", RSEL, 2/2, 1972, pp. 311 у 3/2, 1973, pp. 261-295.

Bosque, I.: "Constricciones morfológicas sobre la coordinación”, Lingüística Española Actual, IX, 1, 1987, pp. 83-100.

Cano Aguilar, R.: "Período oracional y construcción del texto en la prosa medieval castellana", Glosa, nº 1, Córdoba, 1990, pp. 13-30.

----- "La sintaxis del castellano primitivo: oración compleja y estructura discursiva", Actas del IV CIHLE, t. I, La Rioja, Servicio de Publicaciones de la Univ., 1998, pp.17-36

Codoñer, C.: "Parataxis-Hipotaxis", Estudios ofrecidos a E. Alarcos Llorach, III, Oviedo, 1978, pp. 1-12

Cortés Rodríguez, L.: Sobre conectores, expletivos y muletillas en el español hablado, Málaga, Ágora, 1991.

Dardel, R. de: Esquisse structurale des subordonnants conjonctionnels en Roman Commun, Genève, Librairie Droz, 1983.

Dik, S.C.: Coordination. Its implications for the theory of general linguistics, Amsterdam: North Holland, 1968.

Escandell Vidal, $\mathrm{M}^{\mathrm{a}}$ V., "Conectivas: el caso de la conjunción y", Introducción a la pragmática, Ariel, Barcelona, 1996, pp. 157-167.

Franchini, E.: Las condiciones gramaticales de la coordinación copulativa en español, Francke Verlag, Col. Romanica Hervetica, vol. 102, Bern, 1986.

Fuentes Rodríguez, C.: Sintaxis oracional, Sevilla, Alfar, 1985.

----- Enlaces extraoracionales, Sevilla, Alfar, 1987.

---- "Sobre las oraciones consecutivas en el habla urbana de Sevilla (nivel culto)", Lamíquiz-Rodríguez Izquierdo, Sociolingüística Andaluza, 3, Sevilla, Publicaciones de la Univ., pp. 87-103.

---- Aproximación a la estructura del texto, Málaga, Ágora, 1996

----- La organización informativa del texto, Madrid, Arco/Libros, 1999. 
Galmés, A.: Influencias sintácticas y estilísticas del árabe en la prosa medieval castellana, Madrid, Gredos, 1996.

García Calvo, A.: "Ley de ordenación jerárquica de la procesión sintáctica",

Gili Gaya, S.: Curso superior de sintaxis española, Barcelona, Vox, 1985

----- "Fonología del período asindético",

Gutiérrez Ordóñez, S.: Temas, remas, focos, tópicos y comentarios, Madrid, Arco/Libros, 1997.

Jiménez Juliá, T.: “La construcción coordinativa en español”, Verba, 14, 1987, pp. 271345.

----- "De la llamada coordinación negativa en español", Verba, 11, 1984, pp. 213-243.

----- "Disyunción exclusiva e inclusiva en español", Verba, 13, 1986, pp. 163-179.

---- La coordinación en español. Aspectos teóricos y descriptivos, Universidad de Santiago de Compostela, 1995.

Moya Corral, J.A.: "Notas de sintaxis femológica", RSEL, 11/1, 1981, pp. 83-89.

Moreno Cabrera, J.C.: “Tipología de la catáfora paratáctica: entre la sintaxis del discurso y la sintaxis de la oración", ELUA, 3, 1985-86, pp. 165-192.

Narbona, A.: "Problemas de sintaxis coloquial andaluza", RSEL, 16/2, 1986, pp. 229-275.

---- "Don Juan Manuel: El conde Lucanor", Narbona et alii, Textos hispánicos comentados, Córdoba, Universidad, 1984, pp. 39-62

Pietsch, K.: "Zur spanischen grammatik", Homenaje a Menéndez Pidal, T. II, Madrid, 1925.

Real Academia Española: Esbozo de una Nueva Gramática de la Lengua Española, Madrid, Espasa-Calpe, 1998.

Ros García, J.: “Sobre la coordinación en español”, Homenaje al profesor Muñoz Cortés, II, Universidad de Murcia, 1976-1977, pp. 647-657.

Sandmann, M. "Problemas de parataxis", Actas del XI CILFR, t. III, RFE, Anejo LXXXVI, Madrid, 1968, pp. 1369-80.

Serra i Alegre, E.: "Requisitos para la coordinación copulativa con y", Miscel.lània Sanchis Guarner, II, Universidad de Valencia, 1984, 301-305.

----- "El valor comunicativo de la conjunción copulativa", Briz et alii, Pragmática y gramática del español hablado, Actas del II Simposio sobre análisis del discurso oral, Valencia, Libros Pórtico, 1996, pp. 395-399.

Ynduráin: "Más sobre lenguaje coloquial", Español Actual, 6, 1966, pp. 
